\begin{tabular}{|l|l|} 
Jurnal Bimbingan dan Konseling Ar-Rahman \\
Volume 5, Nomor 2, Tahun 2019 \\
Tersedia Online: http://ojs.uniska.ac.id/index.php/BKA \\
e-ISSN 2477-6300
\end{tabular}

\title{
LAYANAN KONSELING KELOMPOK DENGAN TEKNIK BEHAVIORAL CONTRACT UNTUK MENGURANGI PERILAKU MENYONTEK DIKELAS VII SMP NEGERI 9 BANJARBARU
}

\author{
M. Khairul Fathi, M. Yuliansyah, Nurul Auliah \\ Universitas Islam Kalimantan Muhammad Arsyad Al-Banjari \\ fathimtp21@gmail.com
}

\begin{abstract}
ABSTRAK
Perilaku menyontek merupakan perilaku yang tidak terpuji atau perbuatan curang yang dilakukan oleh seseorang yang dilakukan dengan cara menjiplak, meniru, mencontoh atau pun mengambil hasil pekerjaan orang lain baik dengan izin atau tidak disertai izin nya atau pun membuat catatan khusus yang telah dibuat sendiri sebelum menghadapi ujian atau tugas untuk mencapai keberhasilan. Banyaknya siswa-siswi terbiasa melakukan contek menyontek terhadap temannya yang mana perilaku menyontek ini menjadi penyakit didunia pendidikan Tujuan penelitian ini adalah untuk mengetahui tingkat perilaku siswa menyontek sebelum dan sesudah dilakukan layanan konseling kelompok dengan teknik behavioral contract dan keefektifan teknik Behavioral Contract untuk mengurangi perilaku menyontek dikelas VII B. Penelitian ini menggunakan pre-eksperimental design. Eksperimen yaitu one-group pretest dan posttest design kemudian ada penelitian sesudah diberi perlakuan atau posttest dengan begitu hasilnya lebih akurat karena membandingkan keadaan sebelum dan sesudah. Berdasarkan hasil penelitian tingkat perilaku menyontek sebelum diberikan teknik behavioral contract dalam layanan konseling kelompok dengan skor rata-rata $210(70 \%)$ dan sesudah diberikan teknik behavioral contract dalam layanan konseling kelompok dengan diketahui hasil skor rata-ratanya 240 (80\%). Sebagai salah satu rujukan kepada Guru Bimbingan Dan Konseling untuk mengurangi perilaku menyontek siswa disekolah dengan penggunaan teknik behavioral contract dalam layanan konseling kelompok. Bagi siswa, memberi gambaran akan berperilaku jujur dalam belajar atau kebiasaan siswa menyontek karena kejujuran akan memberikan kebaikan untuk diri sendiri. Bagi mahasiswa, agar menjadi referensi kepada penelitian selanjutnya untuk meneliti permasalahan ini.
\end{abstract}

Kata Kunci : Konseling Kelompok; Teknik Behavioral Contract; Perilaku Menyontek

\begin{abstract}
Cheating behavior is behavior that is not commendable or fraudulent committed by someone who is done by plagiarizing, imitating, imitating or taking the work of another person either with permission or not with permission or making special notes that have been made before facing the exam or the task of achieving success. The number of students is accustomed to cheating on their friends whose cheating behavior is a disease in the world of ed. The purpose of this study was to determine the level of behavior of students cheating before and after group counseling services with behavioral contract techniques and the effectiveness of Behavioral Contract techniques to reduce cheating behavior in class VII B. This study uses pre-experimental design. Experiments that is one-group pretest and posttest design then there is research after being treated or posttest so the results are more accurate because it compares the conditions before and after. Based on the results of the research on cheating behavior before being given a behavioral contract technique in group counseling services with an average score of $210(70 \%)$ and after being given a behavioral contract technique in group counseling services, it was found that the average score was 240 (80\%). As one of the references to the Guidance and Counseling Teachers to reduce the cheating behavior of students in school by using behavioral contract techniques in group counseling services. For students, give an idea of behaving honestly in learning or the habit of students cheating because honesty will give goodness to yourself. For students, to be a reference to further research to examine this problem.
\end{abstract}

Keywords : Group Counseling, Behavioral Contract, Cheating Behavior

Dipublikasikan Oleh :

UPT Publikasi dan Pengelolaan Jurnal

Universitas Islam Kalimantan Muhammad Arsyad Al-Banjari Banjarmasin 
M. Khairul Fathi, M. Yuliansyah, Nurul Auliah

Jurnal Bimbingan dan Konseling Ar-Rahman

Volume 5, Nomor 2, Tahun 2019

e-ISSN 2477-6300

\section{PENDAHULUAN}

Perilaku menyontek adalah sebuah fenomena yang sering terjadi dalam dunia pendidikan, tetapi masih kurang diperhatiakan baik dari pendidik maupun masyarakat apalagi di Indonesia ini sendiri. Perilaku menyontek sebagai sebuah sikap yang tidak jujur dalam ujian akan mendapatkan peringatan yang setimpal dari guru atau pengawas ujian. Banyaknya yang menganggap menyontek itu hal yang biasa, padahal masalah meniru merupakan sesuatu yang sangat mendasar didunia pendidikan.

Sari, Marjohan dan Neviyarni (dalam Miranda, 2017:39) Mengatakan saat ini tidak sedikit yang mengungkapkan perilaku menyontek terjadi hampir disetiap jenjang pendidikan. Hal tersebut dapat menghambat terwujudnya tujuan pendidikan nasional diantaranya mewujudkan individu yang berkarakter dan cerdas. Jadi perilaku meniru dalam kelas hampir setiap dipendidikan yang membuat tidak mau berusaha dulu untuk diri sendiri melainkan ingin menghasilkan nilai tinggi tetapi dengan cara mencuri hak milik orang lain atau meniru teman sendiri.

Salah satu cara yang ingin digunakan pada penelitian ini yaitu menggunakan Konseling Kelompok merupakan upaya bantuan yang diberikan kepada peserta didik dalam rangka memberikan kemudahan dalam perkembangan dan pertumbuhannya, konseling kelompok dapat pula bersifat penyembuhan. Konseling kelompok merupakan proses antar pribadi yang dinamis, terpusat pada pemikiran dan perilaku yang sadar, serta melibatkan fungsi-fungsi terapi, seperti sifat permisif, orientasi pada kenyataan, katarsis, saling mempercayai, saling memperlakukan dengan hangat, saling pengertian, saling menerima dan mendukung menurut Nurihsan (dalam Diantini Nur Faridah, 2015:49)

Mengingat banyaknya teknik di dalam konseling maka peneliti menggunakan salah satu teknik yaitu dengan behavioral contrac yang mana mendasari dari suatu permasalahan. Behavioral contract Menurut Rosjiman (dalam Ovila Priska Dewi, 2016:2) mengungkapkan bahwa behaviour contract atau kontrak perilaku adalah perjanjian antara dua orang atau lebih untuk bertingkah laku dengan cara tertentu dan dan untuk menerima hadiah bagi tingkah laku itu. Kontrak ini sangat menegaskan harapan dan tanggung jawab yang harus dipenuhi dan konsekuensinya.

Berdasarkan observasi dan wawancara dengan guru bimbingan dan konseling di SMP Negeri 9 Banjarbaru bahwa seringnya terjadi perilaku contek menyontek dengan teman sekelasnya. Dan faktanya banyak juga hasil laporan tentang permasalahan menyontek ini. Dari sini peneliti menemukan permasalahan yang terjadi didunia pendidikan yang mana bertujuan untuk mengurangi perilaku menyontek tersebut.

Berdasarkan latar belakang masalah diatas serta kenyataan yang ada dilapangan peneliti tertarik untuk mengangkat tema yang berjudul "Layanan Konseling Kelompok Dengan Teknik Behavioral Contract Untuk Mengurangi Perilaku Menyontek DiKelas VII SMP Negeri 9 Banjarbaru"

\section{METODE}

Metode yang digunakan dalam penelitian ini adalah penelitian ini peneliti menggunakan preeksperimental design. Penelitian experimental berhubungan erat dengan adanya pengaruh, yakni adanya variabel $\mathrm{X}$ yang diberikan dalam suatu kondisi atau keadaan khusus, diatur dan dikelola oleh peneliti sehingga dapat memberikan kesan atau akibat pada variabel Y. Peneliti menggunakan eksperimen yaitu one-group pretest dan posttest design kemudian ada penelitian sesudah diberi perlakuan atau posttest, dengan begitu hasilnya lebih akurat karena membandingkan dengan keadaan sebelum diberi perlakuan. Populasi dalam penelitian ini adalah siswa kelas VII SMP Negeri 9 Banjarbaru, yakni berjumlah 29 responden. Menurut Arikunto (2013:174) sampel adalah sebagian atau wakil populasi yang diteliti. Sampel yang diambil dalam penelitian ini adalah. sebanyak 8 siswa dari 29 responden. Kenapa peneliti mengambil sampel 8 orang karena dari 29 responden 8 orang itu yang sering menyontek dari hasil angket atau pre-test. Dari pre test itulah peneliti mengetahui perilaku 8 reponden itu. Sesudah diberikan angket peneliti melakukan treatment dalam beberapa pertemuan lalu peneliti membagi angket lagi atau post-test, disitulah ada perubahan terhadap nilai dari sebelumnya.

Teknik yang digunakan peneliti adalah teknik purposive sampling atau sampel yang bertujuan. Arikunto (2013:183) sampel bertujuan atau purposive sampling dilakukan dengan cara mengambil subjek bukan didasarkan atas strata, random atau daerah tetapi didasarkan atas adanya tujuan tertentu.

\section{HASIL DAN PEMBAHASAN}

Berdasarkam hasil penelitian perilaku menyontek kelas VII B SMP Negeri 9 Banjarbaru sebelum diberikan teknik Behavioral Contract dalam penggunaan layanan konseling kelompok rata-rata 210 (70\%) dan sesudah diberikan teknik behavioral contract dalam penggunaan layanan konseling kelompok maka diketahui hasilnya adalah sebanyak $240(80 \%)$. 
Tabel 1. Hasil Pre-test dan Post-test

\begin{tabular}{|c|c|c|c|c|c|c|c|}
\hline \multirow{2}{*}{ RESPONDEN } & \multicolumn{3}{|c|}{ Pre-test } & \multicolumn{3}{|c|}{ Post-test } & \multirow{2}{*}{$\begin{array}{c}\text { Peningkatan } \\
\text { Skor }(\%)\end{array}$} \\
\hline & Skor & $\%$ & $\mathbf{K}$ & Skor & $\%$ & $\mathbf{K}$ & \\
\hline $\mathrm{RS}$ & 226 & 75 & $\mathrm{~S}$ & 242 & 80 & $\mathrm{~S}$ & 5 \\
\hline $\mathrm{R}$ & 217 & 72 & $\mathrm{~S}$ & 239 & 79 & $\mathrm{~S}$ & 7 \\
\hline DA & 202 & 67 & $\mathrm{~S}$ & 242 & 80 & $\mathrm{~S}$ & 13 \\
\hline $\mathrm{L}$ & 218 & 72 & $\mathrm{~S}$ & 242 & 80 & $\mathrm{~S}$ & 8 \\
\hline MFH & 202 & 67 & $S$ & 238 & 79 & $\mathrm{~S}$ & 12 \\
\hline $\mathrm{EF}$ & 180 & 60 & $\mathrm{R}$ & 233 & 77 & $\mathrm{~S}$ & 17 \\
\hline IAA & 224 & 74 & $\mathrm{~S}$ & 242 & 80 & $\mathrm{~S}$ & 6 \\
\hline $\mathrm{W}$ & 216 & 72 & $\mathrm{~S}$ & 242 & 80 & $\mathrm{~S}$ & 8 \\
\hline RATA-RATA & 210 & 70 & $\mathrm{~S}$ & 240 & 80 & $\mathrm{~S}$ & 10 \\
\hline
\end{tabular}

Untuk membuktikan hipotesis yang diajukan pada penelitian ini yaitu layanan konseling kelompok dengan teknik Behavioral Contract maka diadakan uji dengan analisis Wilcoxon berikut:

Tabel 2. Hasil analisis wilcoxon

\begin{tabular}{cccccc}
\hline Data & $\mathrm{Z}$ & Asym & $<0,0$ & $>0,0$ & Keteran \\
& & p. Sig & 5 & 5 & gan \\
\hline Pretest- & - & 0,012 & Diter & Ditol & Diterim \\
Postest & $\begin{array}{c}2.52 \\
1^{\mathrm{b}}\end{array}$ & & ima & ak & a \\
& & & & & \\
\hline
\end{tabular}

Berdasarkan tabel diatas menunjukkan bahwa data Pre-test dan Post-test hasil analisis menggunakan uji wilcoxon pada aplikasi SPSS menunjukkan nilai Asymp. Sig sebesar 0,012 dengan demikian hasil analisis tersebut diterima karena dasar pengambilan keputusan wilcoxon adalah $<0,05$ yang berarti (Ho) ditolak dan (Ha) diterima karena adanya pengaruh tingkat perilaku menyontek sebelum dan sesudah di berikan layanan konseling kelompok dengan teknik behavioral contract.

Berdasarkan penjelasan hasil penelitian pada Pre-test sebelum diberikan layanan konseling kelompok dengan teknik Behavioral Contract untuk mengurangi perilaku menyontek siswa dikelas VII B, maka diketahui hasil skor Pre-test 8 responden ratarata 210 atau sama dengan $70 \%$. Dan berdasarkan hasil Post-test setelah diberikan perlakuan berupa treatment yaitu dengan layanan konseling kelompok dengan teknik behavioral contract untuk mengurangi perilaku menyontek pada siswa maka diketahui hasilnya adalah sebanyak 240 atau sama dengan $80 \%$. Dengan demikian efektifitas layanan konseling kelompok dengan teknik Behavioral Contract dapat mengurangi perilaku menyontek siswa kelas VII B SMP Negeri 9 Banjarbaru.

Berdasarkan hasil penelitian ini, peneliti mencontoh dari hasil penelitian lain contohnya jurnal dari UNESA yang berjudul : Penerapan Konseling Kelompok Dengan Teknik Behavior Contract Untuk Mengurangi Perilaku Membolos Pada Siswa Di SMK Kawung 2 Surabaya. Yang mana jurnal diatas sebagai acuan peneliti untuk melakukan Layanan diatas dan teknik diatas sebagai acuan peneliti untuk mengurangi permasalahan yang terjadi disekolah.

\section{PENUTUP}

Berdasarkan pada hasil penelitian layanan konseling kelompok dengan teknik behavioral contract untuk mengurangi perilaku menyontek siswa dikelas VII SMP Negeri 9 Banjarbaru sebagai berikut :

a. Perilaku menyontek siswa sebelum diberikan layanan konseling kelompok dengan teknik behavioral contract untuk mengurangi perilaku menyontek dikelas VII B rata-rata skornya 210 dengan persen $70 \%$ dalam kategori sedang dan sesudah diberikan layanan konseling kelompok dengan teknik behavioral contract untuk mengurangi perilaku menyontek dikelas VII B rata-rata skornya 240 dengan persen $80 \%$ dalam kategori sedang. Perubahan sebelum dan sesudah diberikan layanan konseling kelompok dengan teknik behavioral contract untuk mengurangi perilaku menyontek siswa dikelas VII B mengalami peningkatan terhadap skor intervalnya yaitu 30 dengan rata-rata persennya $10 \%$.

b. Sedangkan tinggi tingkat efekivitas layanan konseling kelompok dengan teknik behavioral contract. Berdasarkan hasil perhitungan uji wilcoxon pada data keseluruhan siswa diperoleh bahwa nilai signifikansi (Sig). Sebesar 0,012 kurang dari 0,05. Adanya pengaruh tingkat perilaku menyontek sebelum dan sesudah diberikan layanan konseling kelompok dengan teknik behavioral contract

Berdasarkan hasil penelitian diketahui bahwa perilaku menyontek siswa pada kelas VII B SMP Negeri 9 Banjarbaru, berkenaan dengan hal tersebut peneliti dapat memberikan saran : 
M. Khairul Fathi, M. Yuliansyah, Nurul Auliah

Jurnal Bimbingan dan Konseling Ar-Rahman

Volume 5, Nomor 2, Tahun 2019

e-ISSN 2477-6300

a. Pihak sekolah diharapkan agar memberikan jadwal masuk kelas kepada guru bimbingan dan konseling agar lebih sering memberikan layanan konseling kelompok maupun bimbingan kelompok agar siswasiswa dapat memahami dan mendapat bimbingan untuk menjadi lebih baik lagi.

b. Peneliti selanjutnya agar kiranya dapat benar-benar menggunakan waktu sebaik mungkin untuk melakukan penelitian, apalagi berkaitan dengan konseling kelompok maupun bimbingan kelompok agar mencapai hasil penelitian yang lebih maksimal.

\section{REFERENSI}

Arikunto, S. (2013). Prosedur Penelitian Suatu Pendekatan Praktik Jakarta : Rineka Cipta.

Erford, B.T. (2015). 40 Teknik Yang Harus Diketahui Setiap Konselor Edisi dalam bahasa Indonesia.

Faridah, D.F. (2015). Efektivitas Teknik Modeling Melalui Konseling Kelompok Untuk Meningkatkan Karakter Rasa Hormat Peserta Didik (Quasi Eksperimen Terhadap Siswa Kelas $\mathrm{X}$ di SMK Muhammadiyah 2 Bandung Tahun Pelajaran 2014/2015). Jurnal Bimbingan dan Konseling Islam, 5(1).

Miranda, L.P. (2017). Pengaruh Konformitas Teman Sebaya Dan Minat Belajar Terhadap Perilaku Menyontek Pada Siswa Kelas X SMA Negeri 3 Bontang. Jurnal Psikologi, $5(1): 39-51$.

Nur, A. (2012) Hubungan Antara Motivasi Belajar Dengan Perilaku Menyontek Pada Mahasiswa Fakultas Psikologi Universitas Islam Negeri Maulana Malik Ibrahim Malang. Skripsi. Universitas Islam Negeri Malang.

Dewi, O. P. (2016). Penerapan Konseling Kelompok Dengan Teknik Behavior Contract Untuk Mengurangi Perilaku Membolos Pada Siswa Di SMK Kawung 2 Surabaya. Universitas Negeri Surabaya.

Sugiyono. (2018). Metode Penelitian Pendidikan. Bandung: Afabeta

Samiroh, Z., Immawan, M. (2015). Hubungan Antara Konsep Diri Akademik Dan Perilaku Menyontek Pada Siswa- Siswi Mas Simbakulon Buaran Pekalongan. Jurnal Psikologi Islami, 1(2), 67-77

Wibowo, M. E. (2005). Konseling Kelompok Perkembangan. Semarang. Universitas Negeri Semarang.

Winkle. W.S. dan Hastuti M.M.S (2004). Bimbingan dan Konseling di Institusi Pendidikan (Revised Ed). Yogyakarta: Media Abadi. 